\title{
Auxological evaluation in patients with DiGeorge/ velocardiofacial syndrome (deletion 22q11.2 syndrome)
}

Maria Cristina Digilio, $M D^{1}$, Bruno Marino, $M D^{2}$, Marco Cappa, $M D^{3}$, Paola Cambiaso, $M D^{4}$, Aldo Giannotti, $M D^{1}$, and Bruno Dallapiccola, $M D^{5}$

\begin{abstract}
Purpose: Patients with microdeletion of chromosome 22q11.2 (del22q11) were studied, in order to evaluate auxological parameters and to correlate growth patterns with the presence of main clinical characteristics of the syndrome. Methods: Between January 1995 and March 2000, auxological parameters (weight, height, head circumference, and bone age) of 73 patients with del22q11 were collected. Five subgroups of patients were distinguished: Group I (37 patients) included patients aged between 0.3 and 4 years, Group II (20 patients) included patients aged between 5 and 10 years, Group III (16 patients) included patients aged between 11 and 16.3 years. The presence or absence of some clinical features was correlated to growth patterns. Results: Weight: in Group I, 5 of 37 (13.5\%) patients were below the 3rd percentile, 29 of 37 (78.3\%) were below the mean percentile, none was overweight; in Group II, 13 of 20 (65\%) patients were between the 10th and the 50th percentiles; in Group III, weight corresponded to the 97th percentile in 5 of 16 (31.2\%) patients, and in 2/16 (12.5\%) adolescents, the weight measurements were even above the 97th percentile. Height: short stature was detected in 7 of 73 (9.6\%) of the total patients; the patients with short stature were all $<10$ years old; the height was within the normal age in all adolescent patients. Head circumference: it was below the 3rd percentile in 7 of 73 (9.6\%), between the 3rd and the 25th percentiles in 36 of 73 (49.3\%) patients, between the 25th and the 75 th percentiles in 20 of 73 (27.3\%) patients, and between the 75th and the 97th percentiles in 10 of 73 (13.7\%) patients. Bone age: mean \pm SD bone age was $-0.25 \pm 0.78$ years. Comparisons: the only statistically significant correlation was that between the presence of feeding difficulties and underweight. Conclusion: Auxological parameters of children with del22q11 are characterized by: (1) weight deficiency in the first years of age, (2) weight normalization in the following years, (3) development of obesity in adolescence, (4) short stature in $10 \%$ of the patients, (5) normal height in adolescents, (6) slight delay in bone age in infancy, (7) microcephaly in $10 \%$ of the patients. Genetics in Medicine, 2001:3(1):30-33.
\end{abstract}

Key Words: deletion 22q11.2 syndrome, weight, height, head circumference, bone age.

The DiGeorge/velocardiofacial (DG/VCF) syndrome is due to a microdeletion of chromosome 22q11.2 (del22q11), , ,2 and is clinically characterized by facial dysmorphisms, conotruncal heart defects, palatal anomalies, immunologic defects with thymic hypoplasia, and neonatal hypocalcemia. ${ }^{3-5}$

Growth retardation is reported in $36 \%$ of the patients included in the European collaborative study, ${ }^{5}$ and in $39-63 \%$ of the patients with a clinical diagnosis of DG/VCF syndrome in the series collected before the advent of the microdeletion

From the Departments of ${ }^{1}$ Medical Genetics, ${ }^{2}$ Cardiology, ${ }^{3}$ Pediatrics, and ${ }^{4}$ Endocrinology, Bambino Gesù Hospital, Rome; and ${ }^{5}$ Medical Genetics, La Sapienza University and Mendel-CSS Institute, Rome, Italy.

Maria Cristina Digilio, MD, Medical Genetics, Bambino Gesù Hospital, Piazza S. Onofrio 4, 00165 Rome, Italy.

Received: July 25, 2000.

Accepted: October 25, 2000. studies. ${ }^{1,6-8}$ Growth hormone deficiency has been detected in 4 patients from the literature presenting with extreme short stature, two of whom had pituitary anomalies. ${ }^{9}$

The purpose of this study was to evaluate auxological parameters in our series of children with del22 and to correlate growth patterns with main clinical characteristics of the syndrome.

\section{MATERIALS AND METHODS}

Between January 1995 and March 2000, 73 consecutive patients with del22q11 were evaluated at our hospital in the setting of a follow-up program for DG/VCF syndrome. There were 40 males and 33 females. Their ages ranged from 0.3 to 16.3 years (mean age \pm SD $6.54 \pm 4.46$ years). According to children's ages, five subgroups of patients were distinguished: Group I (37 patients) included patients aged between 0.3 and 4 
years, Group II (20 patients) included patients aged between 5 and 10 years, Group III (16 patients) included patients aged between 11 and 16.3 years. All cases had facial anomalies and clinical characteristics of DG/VCF syndrome, and del22q11 was detectable by fluorescent in situ hybridization with Sc11.1 and Co23 probes ${ }^{10}$ in all cases. The occurrence of features which could influence growth, such as congenital heart defect and cleft palate, was particularly investigated. Anamnestic information about feeding disorders in the first years of age were obtained by interview of the parents. Neuropsychological evaluations were performed according to the Leiter International Performance Scale in patients more than 2 years old.

To evaluate growth in these patients, measurements were taken according to the internationally accepted rules and methods. In particular, weight was measured using a scale. Standing height values were obtained with a Harpender stadiometer, whereas supine length was recorded using a length rigid board for children $<2$ years old. Head circumference was measured using a tape placed around the child's head and passing the prominence of the occiput posteriorly and crossing the forehead superior to the supraorbital ridges. Weight and height/length were plotted on standard percentile growth charts by Tanner et al., ${ }^{11}$ and the closest percentile for age was recorded. Body mass index was calculated by dividing weight (in kilograms) by height squared (meters squared). The stages of pubertal development were evaluated according to Tanner. ${ }^{12}$ Head circumference was compared to standards of Nellhause. ${ }^{13}$ Bone age was determined according to Greulich and Pyle. ${ }^{14}$

Plasma levels of free thyroxin, thyroid stimulating hormone, insulin growth factor 1 were measured using commercial kits.

The presence or absence of some clinical features was correlated to growth patterns. In particular: (1) the finding of underweight (weight below the 3rd percentile) was correlated with the presence of congenital heart defect, cleft palate, and feeding difficulties, (2) the finding of overweight (weight over the 90th percentile) in adolescent patients was correlated with the presence and degree of mental retardation, (3) the finding of short stature (height/length below the 3rd percentile) was correlated with the presence of congenital heart defect and cleft palate, (4) the finding of microcephaly (head circumference below the 3rd percentile) was correlated with the presence of mental retardation. Statistical analysis was performed by chisquare test, and significance was accepted at $P<0.05$.

\section{RESULTS}

\section{Weight}

The distribution among weight percentiles of the patients included in the three age groups are shown in Table 1 and Figure 1. Particularly, in Group I, 5 of 37 (13.5\%) patients were below the 3rd percentile, and 29 of 37 (78.3\%) were below the mean percentile. None of the patients in Group I was overweight. In Group II, 13 of 20 (65\%) patients were between the 10th and the 50th percentiles. In Group III, weight corresponded to the 97 th percentile in 5 of $16(31.2 \%)$ patients, and in 2 of $16(12.5 \%)$ adolescents the weight measurements were even above the 97 th percentile.

\section{Comparisons}

Congenital heart defect was present in 5 of $6(83 \%)$ patients with weight below the 3 rd percentile, and in 58 of 67 (87\%) of those with weight within the normal range. The comparisons were statistically not significant $(P=0.690)$.

Cleft palate was present in 1 of $6(17 \%)$ patients with weight below the 3rd percentile, and in 8 of $67(12 \%)$ of those with weight above the 3 rd percentile. The comparisons were statistically not significant $(P=0.756)$.

Feeding difficulties were referred in 6 of $6(100 \%)$ patients with weight below the 3 rd percentile, and in 21 of 67 (31\%) of those with weight above the 3 rd percentile. The comparisons were statistically significant $(P=0.004)$.

Moderate or severe mental retardation was detected in 5 of $11(45 \%)$ adolescent patients with weight above the 90th percentile, while all adolescents ( 5 patients) with weight below the 90th percentile had normal or only mildly retarded mental development. The comparisons were statistically not significant $(P=0.216)$.

Table 1

Distribution of the patients from our series among weight and height percentiles

\begin{tabular}{|c|c|c|c|c|c|c|c|c|c|}
\hline & \multicolumn{9}{|c|}{ Percentile } \\
\hline & $<3$ rd & $3 \mathrm{rd}$ & 10th & 25 th & 50 th & 75th & 90th & 97 th & $>97$ th \\
\hline \multicolumn{10}{|l|}{ Weight } \\
\hline Patients in Group II $(n=20)$ & 1 & 1 & 6 & 3 & 4 & 1 & 1 & 1 & 2 \\
\hline Patients in Group III $(n=16)$ & 0 & 0 & 1 & 1 & 4 & 1 & 2 & 5 & 2 \\
\hline Patients in Group I $(n=37)$ & 5 & 1 & 3 & 11 & 8 & 5 & 2 & 2 & 0 \\
\hline Patients in Group II $(n=20)$ & 2 & 1 & 6 & 3 & 2 & 2 & 2 & 1 & 1 \\
\hline Patients in Group III $(n=16)$ & 0 & 3 & 2 & 2 & 3 & 1 & 4 & 1 & 0 \\
\hline
\end{tabular}




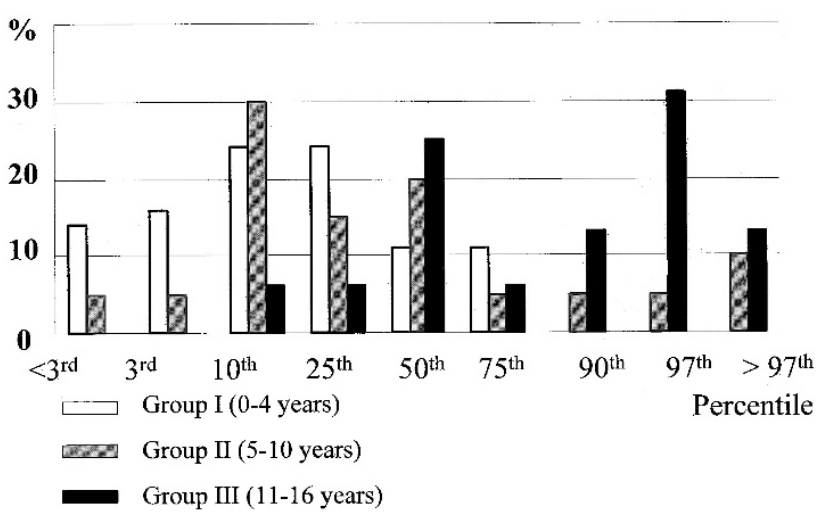

Fig. 1 Distribution in percentages among weight percentiles of the patients from the three different age groups.

\section{Height}

The distribution among height percentiles of the patients included in the three age groups are shown in Table 1 and Figure 2. Short stature (height/length below the 3rd percentile) was detected in 7 of 73 (9.6\%) of the total patients. The patients with short stature were all $<10$ years old. The height was within the normal age in all adolescent patients.

\section{Comparisons}

Congenital heart defect was present in 6 of 7 (86\%) patients with height below the 3 rd percentile, and in 57 of $66(86 \%)$ patients with height above the 3 rd percentile. The comparisons were statistically not significant $(P=0.596)$.

Cleft palate was present in 1 of 7 (14\%) patients with height below the 3 rd percentile, and in 8 of 66 (12\%) patients with height above the $3 \mathrm{rd}$ percentile. The comparisons were statistically not significant $(P=0.661)$.

\section{Body mass index}

Mean \pm SD body mass index was $15.36 \pm 1.34$ in Group I, $16.6 \pm 2.72$ in Group II, $21.81 \pm 3.32$ in Group III.

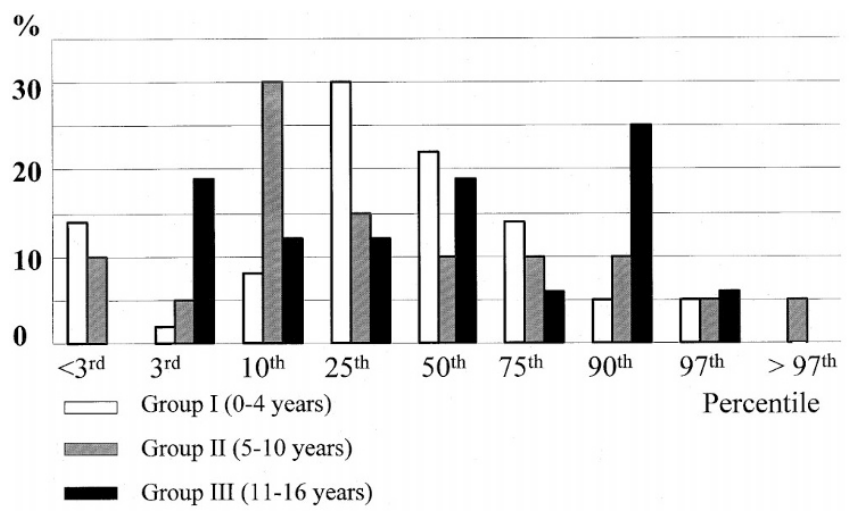

Fig. 2 Distribution in percentages among height percentiles of the patients from the three different age groups.

\section{Pubertal stages}

Pubertal stage corresponded to G1P1 or M1P1 in 60 patients, to G2P2 or M2P2 in 5 patients, to G3P3 or M3P3 in 4 patients, to $\mathrm{G} 4 \mathrm{P} 4$ or M4P4 in 4 patients.

\section{Head circumference}

Head circumference was below the 3 rd percentile in 7 of 73 (9.6\%) patients, between the $3 \mathrm{rd}$ and the 25 th percentiles in 36 of $73(49.3 \%)$ patients, between the 25 th and the 75 th percentiles in 20 of $73(27.3 \%)$ patients, and between the 75 th and the 97th percentiles in 10 of $73(13.7 \%)$ patients.

\section{Comparisons}

Psychometric tests performed in patients more than 2 years old revealed moderate or severe mental retardation in 3 of 7 $(42.8 \%)$ patients with head circumference below the 3 rd percentile, and in 14 of 56 (25\%) patients with normal head circumference. The comparisons were statistically not significant $(P=0.581)$.

\section{Bone age}

Mean \pm SD bone age was $-0.25 \pm 0.78$ years. In Group I, mean \pm SD bone age was $-0.44 \pm 0.45$ years, in Group II was $0.52 \pm 0.57$ years, in Group II was $+0.11 \pm 0.83$ years.

\section{Hormonal dosages}

All patients had normal levels of free thyroxin, thyroid stimulating hormone, and insulin growth factor 1 .

\section{DISCUSSION}

The analysis of growth parameters in our series shows that specific patterns are identifiable in patients with del22q11. Weight deficiency is prevalent in the first years of age, and feeding difficulties seem to be a fundamental risk factor predisposing to growth abnormalities. Feeding problems are common in patients with del22q11, appearing to be mostly due to dysmotility in the pharyngoesophageal area, which is derived from the third and fourth pharyngeal pouches involved in the pathogenesis of the syndrome. ${ }^{15,16}$ It seems that the presence of congenital heart defect or cleft palate has no major impact on the overall growth patterns. In fact, the correlations between the presence of these risk factors and low weight or short stature are statistically not significant, although it must be noticed that patients without congenital heart defect or with cleft palate are a small group in our series. In our experience, the growth in weight improves with time leading to overweight and obesity in adolescence. It seems that adolescent patients with a higher degree of mental retardation are more susceptible to obesity, probably because patients with developmental delay are often sedentary, and have the tendency to eat more.

According to the observation of earlier series of patients with DG/VCF syndrome, short stature is a common feature, the incidence varying from $39 \%$ to $67 \%$ in different series. ${ }^{1,6-8}$ Nevertheless, Young et al. ${ }^{6}$ first suggested that short stature 
could be attributable to constitutional delay, because only $10 \%$ of adult patients in their series were below the normal range. In our series, short stature is detected in about $10 \%$ of the cases, all of whom less that 10 years old. On the contrary, adolescent patients are all normal in height, supporting the presence of constitutional delay in infancy with the possibility to reach a normal stature in the adult age. A mean delay in bone age corresponding to about $4-6$ months is calculated in our infant patients, while bone age is correspondent to chronological age in patients between 10 and 16 years. Growth hormone deficiency has been observed in four patients from the literature, ${ }^{9}$ but none of our patients has hormonal abnormalities.

In conclusion, auxological parameters of children with del22q11 are characterized by weight deficiency in the first years of age prevalently due to feeding difficulties, normalization of weight in the following years, and development of obesity in adolescence, normal final height with a small group of patients showing a constitutional delay in height growth, slight delay in bone age in infancy, and head circumference corresponding prevalently to the lower percentiles.

\section{References}

1. Scambler PJ, Carey AH, Wyse RKH, Roach S, Dumanski JP, Nordenskjold M, Williamson R. Microdeletions within 22q11 associated with sporadic and familial DiGeorge syndrome. Genomics 1991;10:201-206.

2. Driscoll DA, Salvin J, Sellinger B, Budarf ML, McDonald-McGinn DM, Zackai EH Emanuel BS. Prevalence of 22q11 microdeletions in DiGeorge and velocardiofacial syndromes: implications for genetic counseling and prenatal diagnosis. J Med Genet 1993;30:813-817.
3. Lipson AH, Yuille D, Angel M, Thompson PG, Vanderwood KG, Beckenham EJ. Velocardiofacial (Shprintzen) syndrome: an important syndrome for the dysmorphologist to recognize. J Med Genet 1991;28:596-604.

4. Wilson DI, Burn J, Scambler P, Goodship J. DiGeorge syndrome: part of CATCH22. J Med Genet 1993;30:852-856.

5. Ryan AK, Goodship JA, Wilson DI, Philip N, Levy A, Seidel H, Schuffenhauer S, Oechsler H, Belohradsky B, Prieur M, Aurias A, Raymond FL, Clayton-Smith J, Hatchwell E, McKeown C, Beemer FA, Dallapiccola B, Novelli G, Hurst JA, Ignatius J, Green AJ, Winter RM, Brueton L, Brondum-Nielsen K, Stewart F, Van Essen T, Patton M, Paterson J, Scambler PJ. Spectrum of clinical features associated with interstitial chromosome 22q11 deletions: a European collaborative study. J Med Genet 1997;34:798-804.

6. Young D, Shprintzen RJ, Goldberg RB. Cardiac malformations in the velocardiofacial syndrome. Am J Cardiol 1980;46:643-648.

7. Shprintzen RJ, Goldberg RB, Young D, Wolford L. The Velo-Cardio-Facial syndrome: a clinical and genetic analysis. Pediatrics 1981;67:167-172.

8. Goldberg R, Motzkin B, Marion R, Scambler PJ, Shprintzen RJ. Velo-cardio-facial syndrome: a review of 120 patients. Am J Med Genet 1993;45:313-319.

9. Weinzimer SA, McDonald-McGinn DM, Driscoll DA, Emanuel BS, Zackai EH, Moshang T. Growth hormone deficiency in patients with a 22q11.2 deletion: expanding the phenotype. Pediatrics 1998;101:929-932.

10. Dallapiccola B, Pizzuti A, Novelli G. How many breaks do we need to CATCH on 22q11? Am J Hum Genet 1996;59:7-11.

11. Tanner JM, Whitehouse RH, Takaishi M. Standards from birth to maturity for height, weight, height velocity and weight velocity. British children. Arch Dis Child 1966;41:454-471.

12. Tanner JM. Growth and endocrinology of the adolescent. In: Gardner A, editor. Endocrine and genetic disease in childhood. Philadelphia: Saunders, 1975.

13. Nellhause G. Head circumference from birth to eighteen years: practical composite international and interracial graphs. Pediatrics 1968;41:106-114.

14. Greulich W, Pyle S, editors. Radiographic atlas of skeletal development of the hand and the wrist, 2nd Ed. Stanford: Stanford University Press, 1969.

15. McDonald-McGinn DM, Kirschner R, Goldmuntz E, Sullivan K, Eicher P, Gerdes M, Moss E, Solot C, Wang P, Jacobs I, Handler S, Knightly C, Heher K, Wilson M, Ming JE, Grace K, Driscoll D, Pasquariello P, Randall P, Larossa D, Emanuel BS, Zackai EH. The Philadelphia story. The 22q11.2 deletion: report on 250 patients. Genet Couns 1999;10:11-24.

16. Rommel N, Vantrappen G, Swillen A, Devriendt K, Feenstra L, Fryns JP. Retrospective analysis of feeding and speech disorders in 50 patients with velo-cardio-facial syndrome. Genet Couns 1999;10:71-78. 